\title{
Biomaterials
}

Biomaterials 23 (2002) 1981-1987

www.elsevier.com/locate/biomaterials

\section{A study of purified montmorillonite intercalated with 5-fluorouracil as drug carrier}

\author{
F.H. Lin ${ }^{\mathrm{a}}$, Y.H. Lee ${ }^{\mathrm{b}}$, C.H. Jian ${ }^{\mathrm{b}}$, Jau-Min Wong ${ }^{\mathrm{a}}$, Ming-Jium Shieh ${ }^{\mathrm{a}, *}$, Cheng-Yi Wang ${ }^{\mathrm{a}}$

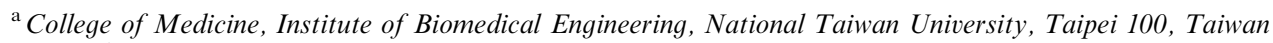 \\ ${ }^{\mathrm{b}}$ Department of Material Science Engineering, National Taiwan University, Taipei, Taiwan
}

Received 7 September 2000; accepted 14 September 2001

\begin{abstract}
Since its introduction over 40 years ago, 5-fluorouracil (5-FU) has remained the only effective chemotherapy option available for the treatment of colorectal cancer (CRC). However, this cytotoxic anticancer drug often causes severe side effects because it does not act selectively on the tumor. It has been reported that the 5-FU showed considerable toxicity when administered by intravenous injections or via alimentary tract. Although, many materials have been developed for carrying 5-FU, there has been no clinically acceptable carrier for 5-FU till now. Montmorillonite, one of the clay minerals, consists of hydrated aluminum silicates with fine grains and large spaces between the layers. Isomorphous substitution of cations is common. In the study, we attempt to intercalate 5-FU into interlayers of montmorillonite through ion exchange.

Montmorillonite was purified from crude clays of bentonite in Tai-dong, Taiwan by filtration and sedimentation. Solutions of 5FU with different concentrations were prepared by dissolving various amounts of 5-FU into $10 \mathrm{ml} \mathrm{NaOH}$ solution. Purified montmorillonite powder was soaked in 5-FU solution for a period of time with different $\mathrm{pH}$ values and temperatures. In this study, we try to intercalate 5-FU into interlayers of montmorillonite to find out optimum conditions, such as soaking time, temperature, $\mathrm{pH}$ value, initial 5-FU concentration, etc., to prepare composites of 5-FU and montmorillonite (5-FU/mont). UV, SDT, FTIR, $\mathrm{XRD}$ are used to characterize the 5-FU/mont composite.

From the results, 5-FU was successfully intercalated into the interlayer of montmorillonite both by free surface absorption and $\mathrm{OH}$ replacement. The optimum condition for 5-FU/mont preparations is $1.185 \mathrm{wt} \%$ of $5-\mathrm{FU}$ as initial concentration under a $\mathrm{pH}$ value of 11.6 at a temperature of $80^{\circ} \mathrm{C}$ and a soaking time of $2 \mathrm{~h}$. The total amount of 5-FU in montmorillonite is about $87.5 \mathrm{mg}$ for each gram of montmorillonite, which can be proved by thermal gravimetric analysis. The composite of 5-FU/mont is expected to achieve in situ release for colorectal cancer therapy in future applications. (C) 2002 Elsevier Science Ltd. All rights reserved.
\end{abstract}

Keywords: 5-Fluorouracil; Montmorillonite; Ion exchange

\section{Introduction}

Colorectal cancer is a major cause for morbidity and mortality in industrialized countries. Generally, surgery is the first-line treatment option for colorectal cancer. For patients with early stage disease, this approach affords a relatively good prognosis, although it is less effective in patients with more advanced disease. For example, patients with lymph node involvement carry a $50 \%$ risk of relapse following resection. For this reason, adjuvant chemotherapy is often prescribed for patients

\footnotetext{
*Corresponding author. Tel.: + 886-2-2366-0390; fax: + 886-2-23940049.

E-mail address: soloman@ha.mc.ntu.edu.tw (M.-J. Shieh).
}

with Dukes' stage C disease in an effort to reduce the high risk of recurrence. For patients with advanced disease, chemotherapy or best supportive care is currently the mainstay of treatment $[1,2]$.

Since its introduction over 40 years ago, 5-fluorouracil (5-FU) has remained the only effective chemotherapeutic option available for the treatment of colorectal cancer. However, response rates achieved with bolus 5FU monotherapy are typically $<10 \%$. Randomized trials have demonstrated clinical benefit in adjuvant and advanced disease settings. Efforts to improve the therapeutic index of 5-FU have included alteration of schedule, and addition of biochemistry modulators. An understanding of 5-FU mechanisms of action has resulted in major therapeutic advances in the past 10 
years; however, a plateau has been reached in the efficacy of 5-FU [3]. One direction vigorously pursued is the development of oral administered fluoropymidines that maintain or improve upon the effectiveness of intravenous 5-FU. There are several potential advantages to oral administration, including patient's convenience and reduced costs associated with drug preparation and administration. Although patients would prefer an oral agent rather than an intravenous one, 5-FU shows incomplete and unpredictable absorption due to its degradation in the gastrointestinal tract. We can design a 5-FU carrier system to release 5-FU just in situ of the cancer area. This may overcome the problem of oral administration of 5-FU in clinical applications $[4,5]$.

In recent years, smectite clays intercalated by polymers have attracted great interest from researchers since they exhibit novel physical and chemical properties. Kato et al. reported that polypropylene oligomer-clay intercalation compounds could be successfully prepared by melt-mixing [6]. PMMA-clay and epoxy-clay hybrid nanocomposite are also newly prepared by emulsion polymerization [7,8]. Montmorillonite, a bioinert clay mineral with fine grain and large inter-planar spacing in the $\left(\begin{array}{lll}0 & 0 & 1\end{array}\right)$ plane, has superior capability to intercalate large molecules into the interlayer space of the $\left(\begin{array}{lll}0 & 0 & 1\end{array}\right)$ plane. The inter-space is more open in basic conditions, especially $\mathrm{pH}$ value over 11 . The structure of montmorillonite is an octahedral laminated sheet, sandwiched between tetrahedral silicate layers $[9,10]$.

In this study, we try to intercalate 5-FU into the interlayer of montmorillonite and to find out an optimum condition such as soaking time, temperature, $\mathrm{pH}$ value, initial 5-FU concentration, etc., to prepare the composite of 5-FU and montmorillonite (5-FU/mont). We hope the composite of $5-\mathrm{FU} /$ mont will reach a goal of releasing 5-FU in situ to treat colorectal cancer in the future clinical application.

\section{Materials and methods}

\subsection{Montmorillonite purificaiton}

The crude clay of bentonite in Tai-dong, Taiwan contains several kinds of clay that includes chlorite, kaolinite, illite, and montmorillonite [11]. Montomorillonite is about $30-40 \%$ by weight in unearthed bentonite. The purifification process is briefly described as follows. One kilogram crude clay was dispersed in $4 \mathrm{~kg}$ of distilled water and then maintained at room temperature for 3 days to wet all the clay minerals. The clay solution was poured into a filtration tank and slowly stirred at a rate of $60 \mathrm{rpm}$. Particles left on the filtration tank were discarded and all the filtered solution was collected. The filtered solution was then centrifuged twice. The supernatant solution was collected and dried by freeze-drying at $-40^{\circ} \mathrm{C}$ for 3 days. The dried powder was identified as pure montmorillonite, which would be used in later experiments.

\subsection{The measurement of cation exchange capacity (CEC)}

The Kjedahl [12] method is used to determine the total sodium sites located in the interlayers of montmorillonite, which can be used to calculate the amount of 5-FU used in the experiment. Total sodium sites in the interlayer of montmorillonite so-called cation exchange capacity. Montmorillonite $(0.1 \mathrm{~g})$ is placed into a centrifuged tube and $30 \mathrm{ml}$ of $1 \mathrm{~N} \mathrm{NH}_{4} \mathrm{OAc}$ is then added. The tube was shaken overnight and centrifuged at $10,000 \mathrm{rpm}$ for $20 \mathrm{~min}$, where sodium ions in the interlayer are totally replaced by $\mathrm{NH}_{4}^{+}$ions. Alcohol $(30 \mathrm{ml})$ was added and shaken for $2 \mathrm{~h}$ to wash out residual $\mathrm{NH}_{4} \mathrm{OAc}$. The $\mathrm{NH}_{4}^{+}$-contained montmorillonite is then soaked into $30 \mathrm{ml}$ of $10 \% \mathrm{NaCl}$ solution, where the $\mathrm{NH}_{4}^{+}$ions in the interlayer would be washed out and have gone into the solution. The supernatant is collected for $\mathrm{NH}_{4}^{+}$ion measurement after centrifugation. The number of measured exchanged $\mathrm{NH}_{4}^{+}$ions represents that of the sodium ions in the original montomorillonite.

\subsection{Soaking time}

The experiment determined how long montmorillonite should be soaked in 5-fluorouracil (5-FU, Sigma Chem. Co., USA) solution to reach a maximum intercalation of 5-FU into the interlayers of montrillonite. $5-\mathrm{FU}(0.06 \mathrm{~g})$ and $0.4 \mathrm{~g}$ of purified montmorillonite powder (1 CEC) are mixed with $10 \mathrm{ml}$ of $\mathrm{NaOH}$ solution with a $\mathrm{pH}$ value of 11.6 in a $50 \mathrm{ml}$ centrifuge tube concomitant with magnetic stirring at $80^{\circ} \mathrm{C}$ for $0.5,1,2$, $4,8,24 \mathrm{~h}$, respectively. After 5 -FU/mont solution was centrifuged at $3000 \mathrm{rpm}$ for $5 \mathrm{~min}$, the supernatant was tipped out and 5-FU concentration in the supernatant was measured by ultraviolet-visible (UV) spectrometer at a wavelength of $270 \mathrm{~nm}$.

\subsection{Reaction temperature}

The experiment determined the temperature of montmorillonite soaked in 5-FU solution to reach a maximum intercalation of 5-FU into the interlayers of montrillonite. 5-FU $(0.06 \mathrm{~g})$ and $0.4 \mathrm{~g}$ of purified montmorillonite powder (1 CEC) are mixed with $10 \mathrm{ml}$ of $\mathrm{NaOH}$ solution with a $\mathrm{pH}$ value of 11.6 in a $50 \mathrm{ml}$ centrifuge tube, which would be stirred at the temperatures $30^{\circ} \mathrm{C}, 40^{\circ} \mathrm{C}, 50^{\circ} \mathrm{C}, 60^{\circ} \mathrm{C}, 70^{\circ} \mathrm{C}, 80^{\circ} \mathrm{C}$, and $90^{\circ} \mathrm{C}$ for $2 \mathrm{~h}$, respectively, by magnetic stirrer. After 5-FU/mont solution was centrifuged at $3000 \mathrm{rpm}$ for $5 \mathrm{~min}$, the 
supernatant was tipped out and 5-FU concentration of the supernatant measured by UV spectrometer at a wavelength of $270 \mathrm{~nm}$.

\section{5. $p H$ value}

The experiment determined the optimum $\mathrm{pH}$ value for montmorillonite soaked in 5-FU solution to reach a maximum intercalation of 5-FU into the interlayers of montmorillonite. The procedure was described as the previous one, where the centrifuge tube was stirred at the $\mathrm{pH}$ values $3,4,5,6,7,8,9,10,11,11.6$, and 12 , respectively, for $2 \mathrm{~h}$ at the temperature of $80^{\circ} \mathrm{C}$. The 5FU left in the supernatant was analyzed by UV spectrometer as in the previous method.

\subsection{Initial 5-FU concentration}

The initial 5-FU loading concentration used in the experiment was determined for optimum 5-FU intercalation. Purified montmorillonite powder $(0.4 \mathrm{~g})$ (1 CEC) was soaked into $\mathrm{NaOH}$ solution with different concentrations of $5-\mathrm{FU}$ in a $50 \mathrm{ml}$ centrifuge tube and then stirred for $2 \mathrm{~h}$ at a temperature of $80^{\circ} \mathrm{C}$ and a $\mathrm{pH}$ value of 11.6. The 5-FU left in the supernatant was analyzed by UV spectrometer as previously described.

\subsection{Characterization and measurements}

UV spectrometer (Perkin-Elmer, Norwalk, 06859CT) measured the concentrations of 5-FU both in the solution and in the interlayer of montmorillonite, with a wavelength of $270 \mathrm{~nm}$. Samples were measured in coupled quartz cells. The concentration in calibration curve was in the range $1.83 \times 10^{-6}-4.67 \times 10^{-4} \mathrm{M} 5$-FU, where $R^{2}$ is 0.9959 . Rigaku X-ray Diffractometer (XRD) obtained X-ray diffraction patterns of the 5-FU/mont composite. The diffraction angle $(2 \theta)$ of the patterns was recorded from $4^{\circ}$ to $40^{\circ}$ with a scanning speed of $4^{\circ} / \mathrm{min}$. $\mathrm{CuK}_{\alpha}$ radiation was used as the $\mathrm{X}$-ray source, which was operated at $30 \mathrm{kV}$ and $20 \mathrm{~mA}$. Silicon powder was used as the standard sample to calibrate the peak position.

Fourier transformed infrared (FTIR) spectra for all the samples were recorded using $\mathrm{KBr}$ pellets (1 mg sample per $300 \mathrm{mg} \mathrm{KBr}$ ) on a Jasco FT/IR-410S grating instrument with slow scan and normal slit width.

The amount of 5-FU in the montmorillonite was determined by thermal gravimetric analysis (TGA) and differential thermal analysis (DTA) performed by a SDT 2960 system (TA Instruments, Inc., 109 Lukens Drive, New Castle, DE 19720). The instrument measures the amount and rate of weight change of a specimen, either as a function of increasing temperature, or isothermally as a function of time, in a controlled atmosphere. At the same time, it can be used to determine the temperatures of endothermic and exothermic transitions at tempera- ture up to $1500^{\circ} \mathrm{C}$. In the study, the analysis temperature was from room temperature to $1100^{\circ} \mathrm{C}$ at a rate of $20^{\circ} \mathrm{C} /$ min. 5-FU composite powder $(10 \mathrm{mg})$ was put into an alumina crucible for analysis and $10 \mathrm{mg}$ of $\alpha-\mathrm{Al}_{2} \mathrm{O}_{3}$ powder was put into the reference port as the reference material.

\section{Results and discussion}

\subsection{Conditions for 5-FU intercalation}

Fig. 1 shows the amount of 5-FU intercalated into the interlayers of montmorillonite with different soaking times. Intercalation of 5-FU in montmorillonite reached a constant value of about $45 \%$ after $1 \mathrm{~h}$ of soaking. The major mechanisms of 5-FU intercalation into the montmorillonite were: (1) 5-FU adsorbed onto the free surface of the montmorillonite; (2) 5-FU replaced sodium in the interlayer; and (3) 5-FU replaces clay $\mathrm{OH}$ groups to form ionic bonds with $\mathrm{Al}^{3+}$ and $\mathrm{Mg}^{2+}$ in the montmorillonite. The former two mechanisms were presumed as the major mechanisms for 5-FU absorbed onto the montmorillonite by a concentration gradient. When the concentration gradient was equal between inside and outside of the montmorillonite, the diffusion would stop after soaking for a period of time. In order to reduce the soaking time and avoid the incomplete intercalation, we selected $2 \mathrm{~h}$ as the optimum soaking time in the later experiments.

The relationship of 5-FU intercalation and reaction temperature is shown in Fig. 2. Amounts of 5-FU in the montmorillonite increase with the reaction temperature but decreased after $80^{\circ} \mathrm{C}$. The concentration gradient at a specific point along the diffusion path changes with time $t$. This diffusion condition is represented by a second-order differential equation (Fick's second law) [13]

$$
\left(\partial C_{x} / \partial t\right)=D\left(\partial^{2} C_{x}\right) / \partial X^{2}
$$

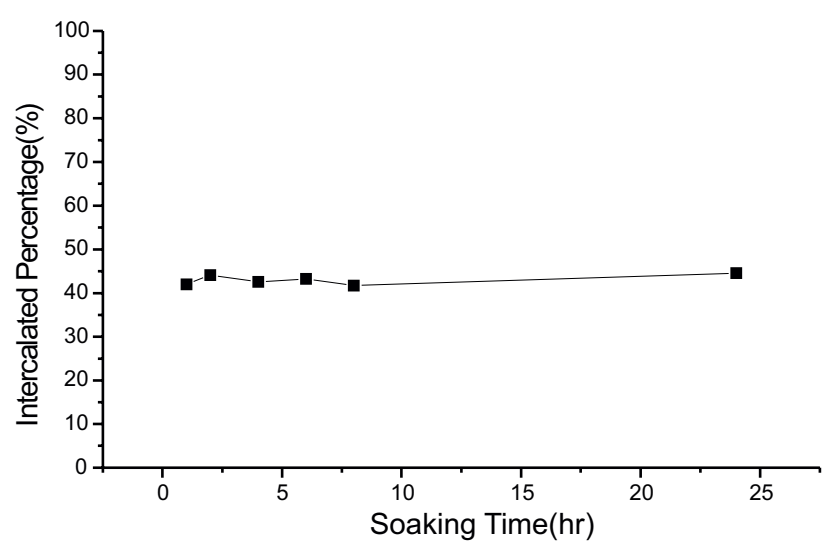

Fig. 1. Intercalation of 5-FU at different soaking times. 


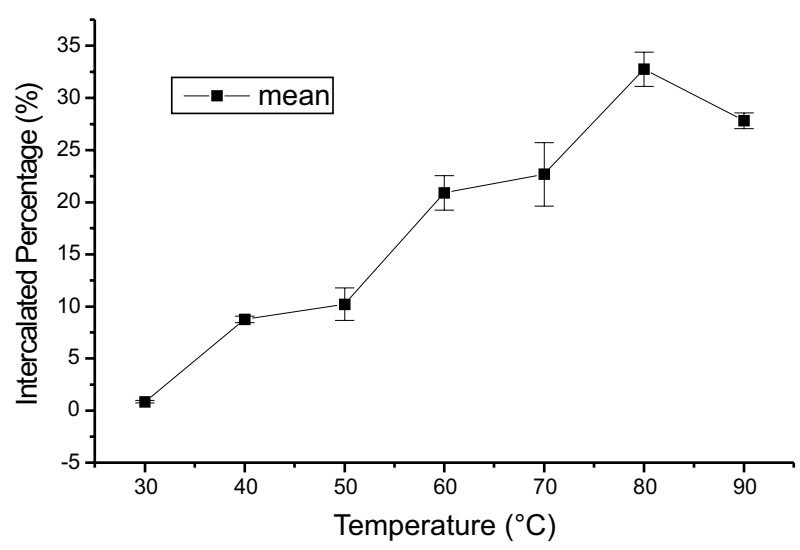

Fig. 2. Interaction of 5-FU at different temperatures.

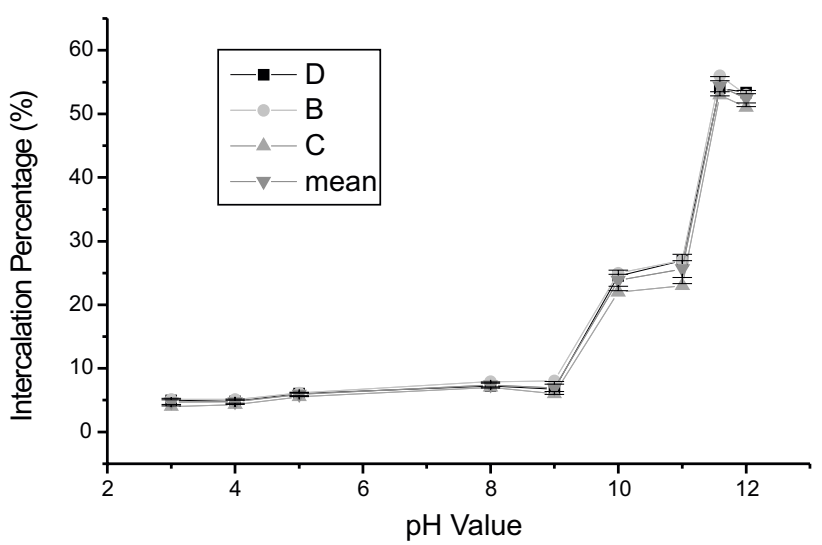

Fig. 3. 5-FU intercalation at different $\mathrm{pH}$ values.

where $D$ is the diffusion coefficient, which can be expressed as [14]:

$D=D_{0} \mathrm{e}^{-q / k T}$.

$D$ increases with the temperature $T$, which will promote more diffusion processes at higher temperature. Although there were no significant differences in the amount of 5-FU intercalated in montmorillonite at reaction temperatures of $80^{\circ} \mathrm{C}$ and $90^{\circ} \mathrm{C}, 80^{\circ} \mathrm{C}$ was chosen as suitable intercalated temperature due to the risk of 5-FU damage at higher temperature.

Fig. 3 shows the effect of $\mathrm{pH}$ value on the intercalation of 5-FU in the montmorillonite. No significant differences for the 5-FU intercalation were noted when the $\mathrm{pH}$ value was in the range 3-9. The amount of 5-FU intercalation shows a sharp increase with $\mathrm{pH}$ value over 9. The intercalation reached a plateau after $\mathrm{pH}=11.6$. The $d$-spacing of interlayer of montmorillonite would be more open at higher $\mathrm{pH}$ values, especially under very basic conditions [15]. It has been proved in many reports that the characteristic peak of $\left(\begin{array}{lll}0 & 0 & 1\end{array}\right)$ in montmorillonite on XRD patterns had a great shift to a lower angle.

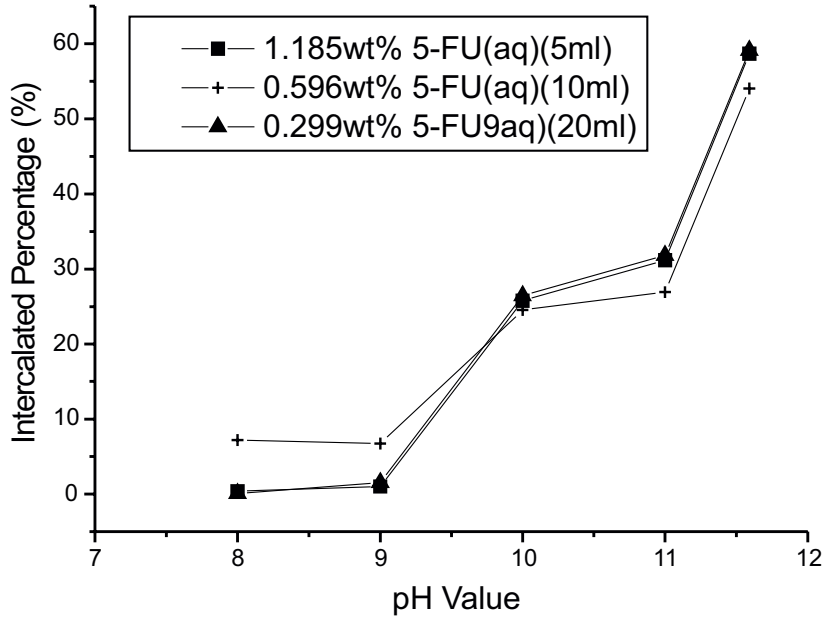

Fig. 4. The intercalation of 5-FI at different initial 5-FU loading concentrations.

More open is the structure and the space available in the interlayer, the more 5-FU should be intercalated into the montmorillonite.

It appears that intercalation of 5-FU in montmorillonite is not affected by the initial 5-FU concentration in the solution, as shown in Fig. 4. The initial concentration of 5-FU in the solution should increase the intercalation rate due to greater concentration gradient at the initial stage. However, it will not affect the final amount of 5-FU intercalated in montmorillonite due to the limit-replaced sites of sodium and $\mathrm{OH}$ group in the structure of montmonrillonite.

\subsection{Thermal analysis of 5-FU/mont composites}

Curve A on Fig. 5 is the TGA profile for pure montmorillonite. There are three steps for weight loss at the temperature around $120-140^{\circ} \mathrm{C}, 510-700^{\circ} \mathrm{C}$, and $900^{\circ} \mathrm{C}$. We could trace one strong and two weak endothermic peaks on the DTA pattern of pure montmonrillonite at the same temperature range, as shown on curve A of Fig. 6. The first weight loss and the strong endothermic peak at the temperature around $120-140^{\circ} \mathrm{C}$ was due to the free water evaporation. The second and the third weight loss at the temperature around $510-700^{\circ} \mathrm{C}$ and $900^{\circ} \mathrm{C}$ were due to the $\mathrm{OH}$ group release from different position of the montmorillonite structure [16].

Curve $\mathrm{B}$ in Fig. 5 is the TGA curve of montmorillonite blended with 5-FU. It shows an obvious weight loss at the temperature around $200-290^{\circ} \mathrm{C}$, corresponding to the 5-FU removal. Other weight losses at curve B of Fig. 5 is the same with the pure montmorillonite as shown in curve A of Fig. 5. Curve B of Fig. 6 is the DTA pattern of montmorillonite blended with 5-FU. We can trace an endothermic peak at $280^{\circ} \mathrm{C}$ that is due to $5-\mathrm{FU}$ 


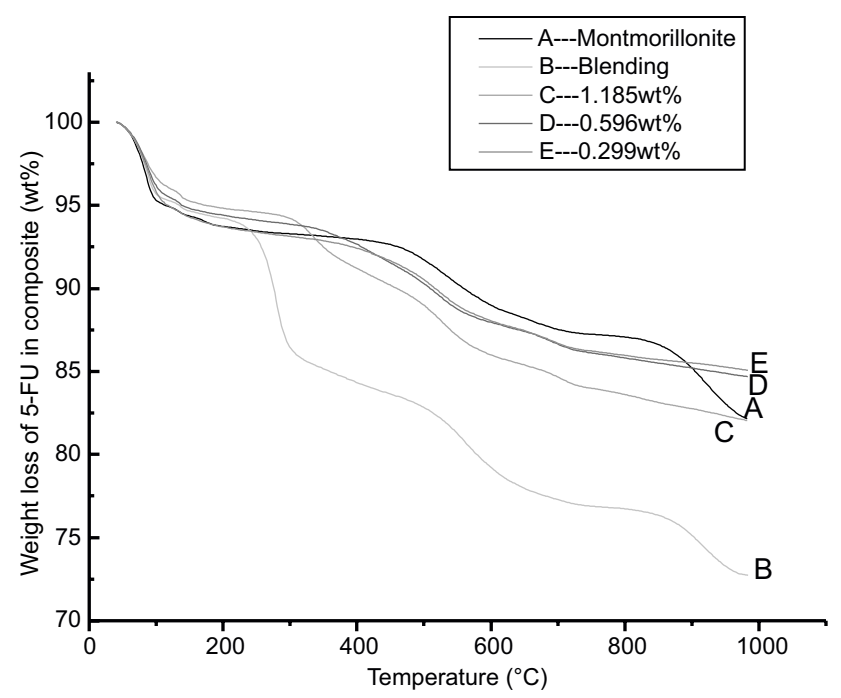

Fig. 5. TGA curve (A) pure montmorillonite (B) 5-FU blended with montmorillonite (C) 5-FU/mont composite prepared at a initial concentration of $1.185 \%$, (D) prepared at a initial concentration of $0.596 \%$, (E) prepared at a 5 -FU initial concentration of $0.299 \% H=$ 11.59 , at $37^{\circ} \mathrm{C}, 5-\mathrm{FU}+$ montmorillonite (D) $0.596 \% 5-\mathrm{FU}$ solution, at $\mathrm{pH}=11.59,37^{\circ} \mathrm{C}$, for $2 \mathrm{~h}$.

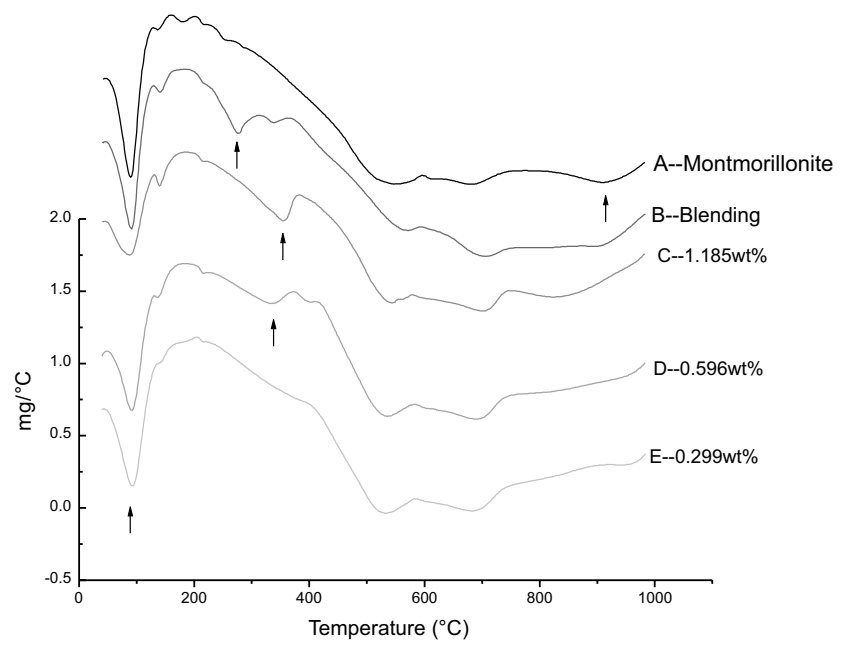

Fig. 6. DTA curve (A) pure montmorillonite (B) 5-FU blended with montmorillonite (C) 5-FU/mont composite prepared at a initial concentration of $1.185 \%$, (D) prepared at a initial concentration of $0.596 \%$, (E) prepared at a 5 -FU initial concentration of $0.299 \% H=$ 11.59 , at $37^{\circ} \mathrm{C}, 5-\mathrm{FU}+$ montmorillonite (D) $0.596 \% 5$-FU solution, at $\mathrm{pH}=11.59,37^{\circ} \mathrm{C}$, for $2 \mathrm{~h}$.

decomposition. The other endothermic peaks are identified as the same with those of curve A in Fig. 6.

The TGA curve and the DTA pattern of 5-FU intercalated into the interlayer of montmorillonite with an initial concentration of $1.185 \mathrm{wt} \%$ are shown in curve C of Figs. 5 and 6, respectively. The first weight loss and endothermic peak on the curve $C$ of Figs. 5 and 6 is due to free water evaporation. The second weight loss and endothermic peak at the temperature around $360^{\circ} \mathrm{C}$ is due to 5-FU decomposition. We can observe that the endothermic peak at a temperature of $280^{\circ} \mathrm{C}$ on curve B of Fig. 6 shifts to $360^{\circ} \mathrm{C}$ on the curve $\mathrm{C}$ of Fig. 6 . It reflects that the $5-\mathrm{FU}$ is partly intercalated into the interlayer of montmorillonite and takes the position of $\mathrm{OH}$ groups in the montmonrillonite structure. This replacement will lead 5-FU to decompose at a higher temperature, and cause the last endothermic peak at a temperature of $900^{\circ} \mathrm{C}$ on curve $\mathrm{C}$ of Fig. 6 to disappear because $\mathrm{OH}$ is replaced by 5-FU during intercalation. The last step of weight loss on the curve $\mathrm{C}$ of Fig. 5 also vanished as expected due to the same reason. Part of 5FU is adsorbed onto the free surface of the montmorillonite or takes the place of sodium ions in the interlayer, corresponding to the second weight loss in curve $\mathrm{C}$ of Fig. 5. Curves E and D of Fig. 6 are the TGA curves of 5-FU intercalated into montmorillonite with a initial concentration of 0.596 and $0.299 \mathrm{wt} \%$, respectively. We can recognize a weak endothermic peak around $900^{\circ} \mathrm{C}$ that means that $\mathrm{OH}$ groups are not totally replaced by the 5-FU during intercalation. Most of the 5-FU in montmorillonite show free surface adsorption and sodium ion replacement. The 5-FU evaporation at the temperature around $330^{\circ} \mathrm{C}$ on curve $\mathrm{D}$ of Fig. 6 is also a support for $\mathrm{OH}$ group replacement. Although the initial concentration of 5-FU did not affect the amount of 5-FU intercalating into the montmorillonite, it would cause 5-FU to be intercalated through a different mechanism. The mechanism of $\mathrm{OH}$ replacement will reach a slow release of 5-FU in vivo that will be discussed in the other report. The optimum of intercalation for the initial concentration of 5-FU is $1.185 \mathrm{wt} \%$ (1 CEC). The total amount of 5-FU intercalated into montmorillonite is about $87.5 \mathrm{mg}$ for each gram of montmorillonite, under the condition of an initial concentration of $1.185 \mathrm{wt} \%, 80^{\circ} \mathrm{C}, 11.6$ of $\mathrm{pH}$ value, and a soaking time of $2 \mathrm{~h}$.

\subsection{FTIR and XRD analysis}

Fig. 7 illustrates the spectra from pure montmorillonite, pure 5-FU, and 5-FU/mont composite prepared at the optimum condition, respectively. In the spectrum of pure montmorillonite, the absorption bands at 1043 and $482 \mathrm{~cm}^{-1}$ are the stretching vibrations of clay $\mathrm{Si}-\mathrm{O}$. The characteristic band at $932 \mathrm{~cm}^{-1}$ is $\mathrm{Al}-\mathrm{Al}-\mathrm{OH}$ stretching in the octahedral layer and at $541 \mathrm{~cm}^{-1}$ is $\mathrm{Al}-\mathrm{O}-\mathrm{Si}$ stretching mode $[17,18]$. For pure 5-FU, the absorption bands at 1725,1672 , and $1247 \mathrm{~cm}^{-1}$ are responsible for cyclic imide, $\mathrm{CO}-\mathrm{NH}-\mathrm{CO}$, imide, amide $\mathrm{I}$ band $(\mathrm{C}=\mathrm{O})$, and amide III band $(\mathrm{C}=\mathrm{O})$, respectively [19]. Not only all the characteristic bands belonging to pure montmorillonite and 5-FU appear in the spectrum of the 5-FU/ mont composite, some absorption bands at 1310 and 1610 that is supposed to be Al-5-FU are also recognized. From the result, we can learn that the 5-FU in 


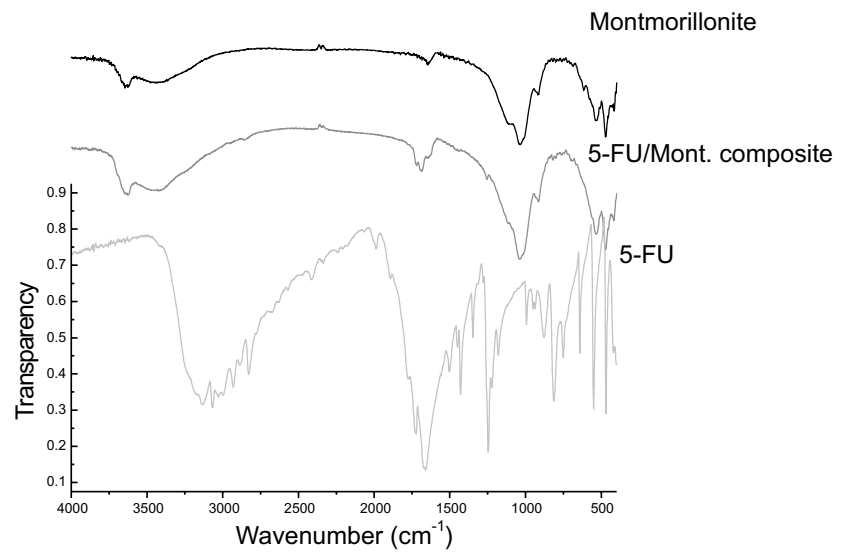

Fig. 7. FT-IR spectra of pure montmorillonite, 5-FU, and 5-FU/mont composite.

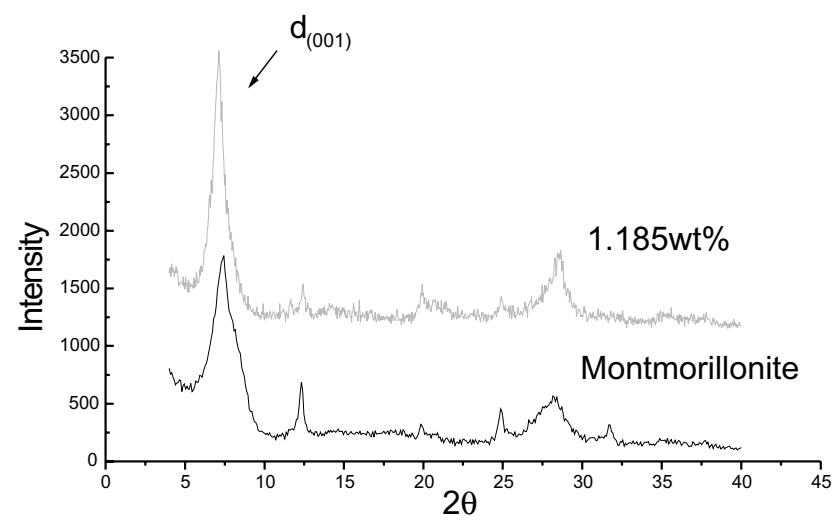

Fig. 8. XRD patterns of 5-FU/mont composite and montmorillonite.

montmorillonite is not only attached on the free surface by adsorption but also forms chemical bonds within montmorillonite.

Fig. 8 shows the XRD pattern of pure montmorillonite and 5-FU/mont composite prepared in optimum conditions. Most of the characteristic peaks in the two patterns are in the same position. The characteristic peak of $(001)$ for pure montmorillonite is at a position of $7.5^{\circ}$, but that of $5-\mathrm{FU} /$ mont composite is at $7^{\circ}$. According to the Bragg Law [20]: $\lambda=2 d \sin \theta$, the peak shifting from higher diffraction angle to lower diffraction angle is due to $d$-spacing increase. Compared to pure montmorillonite, the $5-\mathrm{FU} /$ mont composite has a more open structure at the plane of $\left(\begin{array}{lll}0 & 0 & 1\end{array}\right)$. It is also one of the evidence that 5-FU has been successfully intercalated into the interlayer of montmonrillonite.

\section{Conclusion}

In this study, 5-FU has been confirmed to successfully intercalate into the interlayers of montmonrillonite both by free surface adsorption, and sodium and $\mathrm{OH}$ replacement. The optimum condition for $5-\mathrm{FU} / \mathrm{mont}$ preparations is $1.185 \mathrm{wt} \%$ of $5-\mathrm{FU}$ initial concentration under a $\mathrm{pH}$ value of 11.6 , at the temperature of $80^{\circ} \mathrm{C}$ and with a soaking time for $2 \mathrm{~h}$. The total amount of 5FU in montmorillonite is about $87.5 \mathrm{mg}$ for each gram of montmorillonite, which can be proved by TGA.

\section{Acknowledgements}

The authors would like to gratefully acknowledge the NHRI of ROC for the financial support of this research.

\section{References}

[1] Ishikawa T, Utoh M, Sawada N, Nishida M, Fukase Y, Sekigochi F, Ishitsuka H. Tumor selective delivery of 5-Fluorouracil by capecitabine, a new oral fluoropyrimidine carbamate, in human cancer xenografts. Biochem Pharmacol 1998;55:1091-7.

[2] Meropol NJ. Clinical oncology update, oral fluropyrimidines in the treatment of colorectal cancer. Eur $\mathbf{J}$ Cancer 1998;34(10):1509-13.

[3] Bleiberg H. Review, colorectal cancer-is there an alternative to 5-FU? Eur J Cancer 1997;33(4):536-41.

[4] Haller DG. An overview of adjuvant therapy for colorectal. Eur J Cancer 1995;31A(7/8):1255-63.

[5] Bajetta E, Di Bartolomeo M, Somma L, Del Vecchio M, Artale S, Zunino F, Bignami P, Magnani E, Buzzoni R. Doxifluridine in colorectal cancer patients resistant to 5-Fluorouracil (5-FU) containing regimens. Eur J Cancer 1997;33(4):687-90.

[6] Kato M, Usuki A, Okada A. Synthesis of polypropylene oligomer-clay intercalation compounds. J Appl Polym Sci 1997;66:1781-5.

[7] Lee DC, Jang LW. Characterization of epoxy-clay hybrid compositre prepared by emulsion polymerization. J Appl Polym Sci 1998;68:1997-2005.

[8] Lee DC, Jang LW. Preparation and charaterization of PMMAclay hybrid composite by emulsion polymerization. J Appl Polym Sci 1996;61:1117-22.

[9] Bremner JM. Methods of soil analysis. Madison, WI: American Society ofAgronomy Inc. Part 2, Agronomy 9, 1149-1225, 1324-48.

[10] Boyd SA, Lee JF, Mortland MM. Attenuating organic contaminant mobility by soil modification, 1988.

[11] Hugh Powell D, Kowut Tongkhao, Kennedy SJ, Slade PG. A neutron diffraction study of interlayer water in sodium wyoming montmorillonite using a novel difference method. Clays Clay Miner 1997;45(2): 290-4.

[12] Bremner JM. Total nitrogen, inorganic forms of nitrogen, organic forms of nitrogen, nitrogen availability indexes. In: Black CA, et al., editors. Methods of soil analysis, Part 2. p. 1149-1255, 1324-48.

[13] Reed-Hill RE, Abbaschian R, editors. Physical metallurgy principles, 3rd ed. PWS Publishing Company, 1994. p. 373-6.

[14] Shackelford JF, editor. Introduction to materials science for engineers, 3rd ed. New York: Macmillan Publishing Company, 1992. p. 146-7.

[15] Duh BT. Study on sodium alginate/montmorillonite complexes in argriculture application-drug delivery system. Master thesis, Department of Material Science, Engineering, National Taiwan University, 1999. 
[16] Hutchison CS, editor. Laboratory handbook of petrographic techniques. New York: McGraw-Hill Book Co., 1973. p. 456.

[17] Komadel P, Bujdak J, Madejova J, Sucha V, Elsass F. Effect of non-swelling layers on the dissolution of reduced-charge montmorillonite in hydrochloric acid. Clay Miner 1996;31: $333-45$.
[18] Nasser A, Gal M, Gerstl Z, Mingelrin U, Yariv S. Adsorption of alachlor by montmorillonite. J Thermal Anal 1997;50:257-68.

[19] Socrates G, editor. Infrared characteristic group frequencies. Uxbridge, Middlesex: Brunel University.

[20] Reed-Hill RE, Abbaschian R, editors. Physical metallurgy principles, 3rd ed. PWS Publishing Company, 1994. p. 33-7. 